\title{
Comeback and Development of Large Format Photography in the Era of Digital Photography
}

\author{
Yang Zhi \\ Hunan University of Humanities, Science and Technology \\ Loudi, Hunan
}

\begin{abstract}
With the arrival of the era of fast-food-style digital photography, tremendous changes has taken place in photography. However, large format photography still has its unique charm. Why we choose large format while phone photography is popular today? Why we still choose film cameras while digital ones are increasingly powerful? Why large format photography is still of great importance in modern artistic photography. The reason is that pictures shot by large format cameras have unparalleled visual artistic effects, which can give traditional photography the implication of thoughts. This paper first introduces the origin and characteristics of large picture photography. Secondly, this paper introduces the application of large-format photography in art photography, landscape photography and commercial photography, and expounds the value and significance of contemporary large-format photography. It is found that large painting plays an important role in the detail and quality of the works.
\end{abstract}

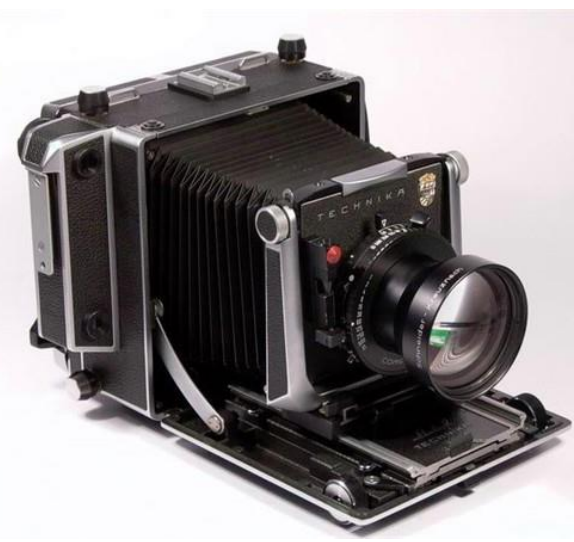

Fig. 1. Large format camera
Keywords-The era of digital photograph; Comeback and development; Large format; Value

\section{TRADITIONAL LARGE FORMAT PHOTOGRAPHY}

\section{A. The origin of large format photography}

Large format appeared about 300 years before the invention of photography, when European draftsmen and case ", which was the basic form of large format cameras. In the summer of 1862, French inventor Joseph Nicéphore Nièpce coated white wax impression and shot in a black case, gaining the first forever preserved photo. After 1839, LouisJacques-Mandé Daguerre invented Daguerreotype and shot with improved large format cameras and obtained unexpected artistic effects. painters began using a assistive tool for painting called "black

\section{B. Traditional large format photography}

Photography is divided into traditional photography and digital photography. The latter is now a medium can be used buy everyone. Traditional photography, whose process is far more complex than that of digital photography, relies on films, so it expects more from photographers. Traditional photographers should know both shooting and darkroom skills. They need to work patiently and carefully. This DIY working method can let shutterbugs enjoy the pleasures brought by large format cameras during their creation process.

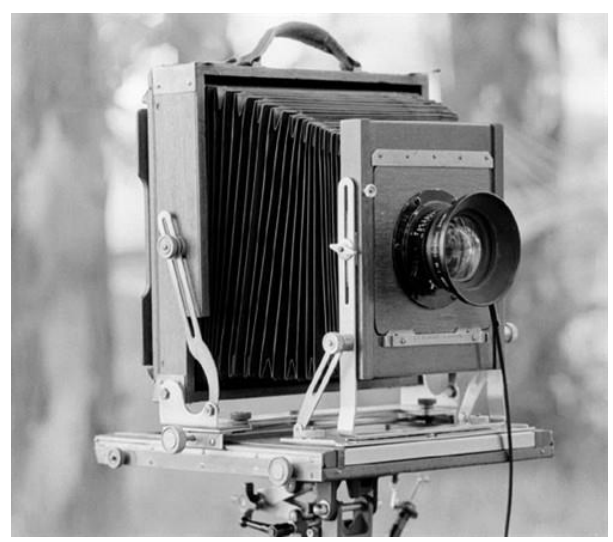

Fig. 2. Large format camera

\section{MAIN APPLICATION FIELDS OF LARGE FORMAT PHOTOGRAPHY}

As large format cameras can produce pictures with high definition, high quality, realism and vivid hues and colors, it is popular in many fields. It not only has its position in artistic photography, but plays an important role in commercial photography. Besides, it is drawing more and more attention in landscape photography. Big negative films used by large format cameras bring fine and clear descriptions to many artists' works, genuinely matching virtuality and reality, 
details and gradations within an image. The tones, graininess and realism brought by large format cameras can never be surpassed by those by small-sized cameras. If you need high quality images, the "details" brought by large format cameras will stun you. With large format cameras, you can control perspective relations and adjust the focus of your camera, creating special effects. In the shooting process, large format cameras can avoid certain obstacles and produce nondeforming photos. They can also change perspective and control the range of clearness, giving photographers' shooting process a strong sense of ceremony.

\section{MAIN FIELDS LARGE FORMAT PHOTOGRAPHY IS APPLIED}

IN

\section{A. Large format in artistic photography}

Because of its long peroid of processing, the artistry of large format photography is admired by photographers. On the Eve of the 2018 spring festival, invited by Inner Monglia Large Format Invitation Exhibition, 35 photographers across China exhibited their works in Aijia Milai Cultural Centre. On the exhibition, there were not only works made by traditional techniques, such as silver prints and platinum prints, but also gorgeous works produced with the help of modern digital microprinting. All the works reflected the charm of photographic art.

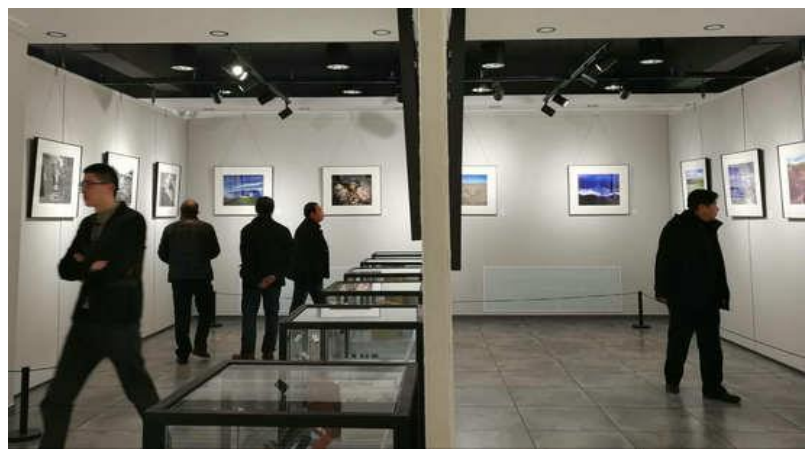

Fig. 3. Invitation exhibition held in Inner Mongolia

\section{B. Large format in landscape photography}

In landscape photography, few people shoot with large format cameras, which are not portable. However, big photographic plates of large format cameras can better record the perspective and rich variations of the big world. Many photographers will utilize the adjustment function of large format cameras to control the perspective relationships within a picture, especially the location OGTT the focus, whereby gaining pictures of high sharpness. With the development of digital photography, traditional photography is reviving. Now many excellent photographers take landscape pictures with large format cameras.

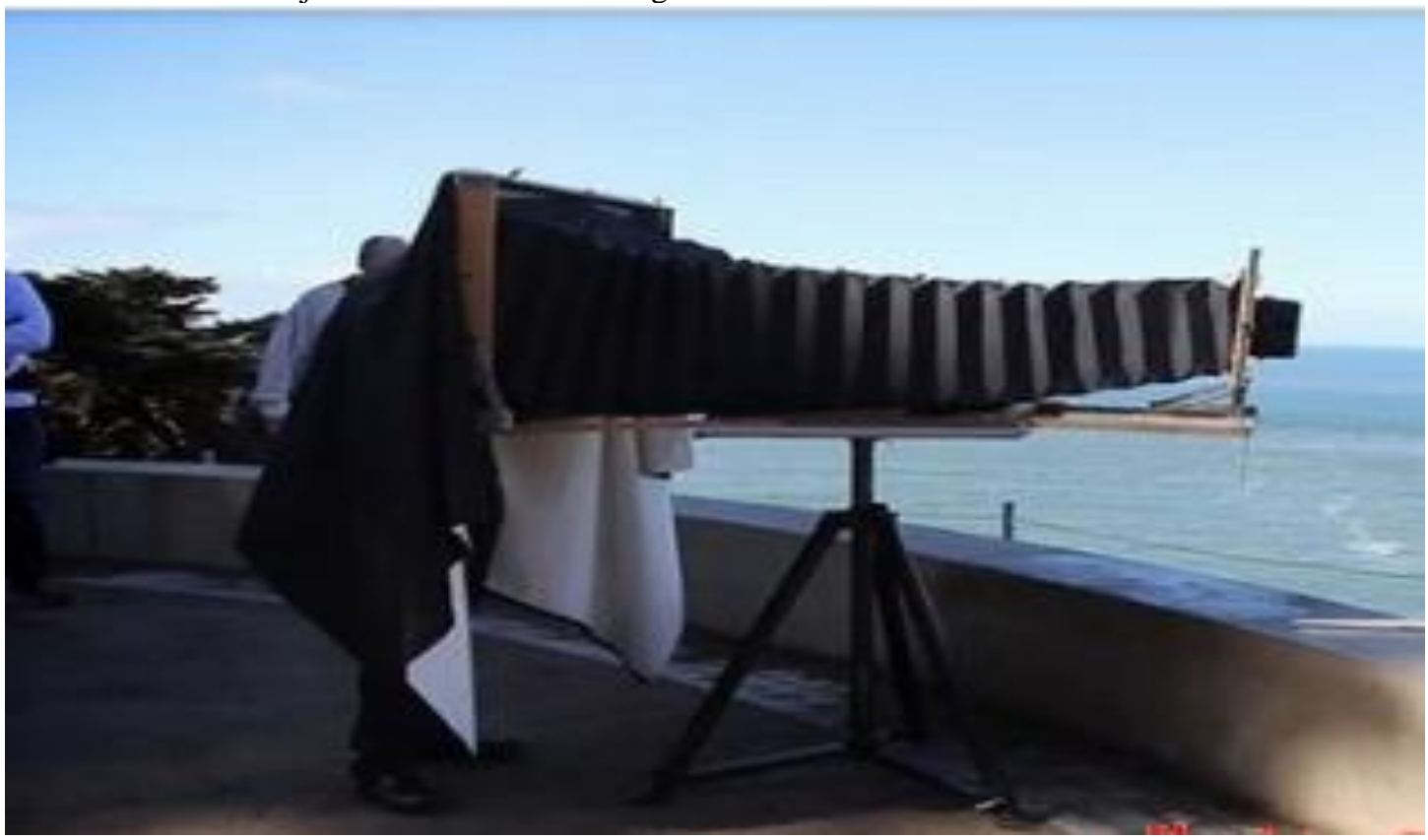

Fig. 4. A photographer is taking landscape pictures with a large format camera 


\section{Large format in cmercial photography}

Large format not only plays a role in artistic and lanscape photography, but also a certain role in comercial photography. It is a custimized service to meet high-end demands. For example, the service of shooting permanently preserved family photos is popular among people with advanced comsuption concepts. At the same time, the visual effect of photography, with perfect details, harmonious hues and large image sizes, is extremely good, which can always satisfy comsumers. The common business model is taking portraits with large format cameras and process them in darkrooms, whereby producing stunning pictures.

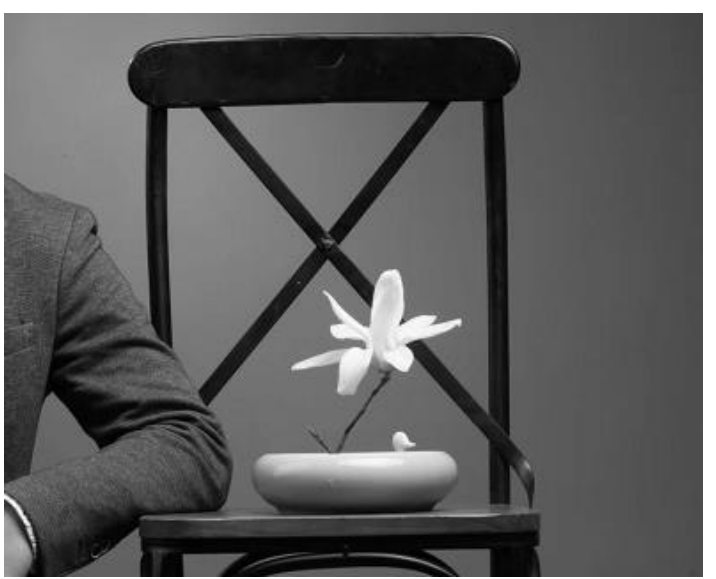

Fig. 5. Still life shot by large format camera

\section{VALUES AND MEANINGS OF MODERN LARGE FORMAT PHOTOGRAPHY}

\section{A. Details of works brought by large format cameras}

Since the birth of small-sized cameras and camera phones, people have been getting used to snap and record momentary images through simple shooting. But the gradations and details of photos are completely lost. While large format cameras can better show the realism and details of objects, which not only because that the fine image effects brought by big negative films that cannot be achieved by many small-sized cameras, but also that large format cameras emphasize more on the expression of details and the display of every detail. Although the subjects of photography are relatively static, they provide photographers with more thinking space when they shoot photos. One cannot get a picture through random shooting. Only by meticulous composition and tuning can one large format photo that can retain time and memory.

\section{B. Quality of works displayed by large format cameras}

The shooting process of large format cameras is very rigorous. And its production is also both time- and energyconsuming. In recent years, many artists created works through photography. However, their works could not achieve the quality required by exhibitions because of their big sizes. Therefore, shooting with large format cameras become a good choice for them. The quality of images delivered in postproduction is quite important and large format cameras can meet the high quality display of works.

\section{The thought value of traditional large format photography}

Photography by smart phones and small-sized cameras is a shooting method in this fast-paced age, which emphasizes on momentary intuition and instinct inspiration. But large format photography pays more attention to rational thinking and the decorous feeling of photography. In the process of large format shooting, photographers stress more on the continuity and constancy of works, which requires low pace. In the slow shooting process, they can enjoy the pleasure brought by large format photography. Photographers who like large format photography also develop a set of methods of observation, thinking and a lifestyle. The technique of large format photography after shooting is printing photos on photographic paper, which needs more manpower and money. Pictures produced in darkrooms show their uniqueness and historical value, so many photographers regard large format photography as a luxury.

\section{CONCLUSION}

In this fickle era, the fast-paced lifestyle gradually submerges many traditional skills and cultures, which is realized by more and more people. The comeback and development of large format photography in the era of digital photography provides shutterbugs who love and specialize in traditional photography with more choices and possibilities in a unique way and require them to have a positive attitude to their objects. In the age of visual photography, large format cameras enable photographers develop a unique lifestyle, which emphasize the person-to-person and human-to-nature communication. Therefore, the comeback and development of large format photography in the era of digital photography is more of the implication of thought.

\section{REFERENCES}

[1] Feng, Jianguo. Large Format Photography. Hangzhou: Zhejiang Photographic Press, 2007.

[2] Jeffery, Ian. Photography: A Concise History. Beijing: SDX Joint Publishing Company, 2002.

[3] Feng, Jianguo. Black-and-white Photography. Hangzhou: Zhejiang Photographic Press, 2005.

[4] Sontag, Susan. On Photography. Changsha: Hunan Fine Art Press, 2005.

[5] Sha, Zhanxiang. Photographic Lenses: Characteristics and Guide to Purchase. Beijing: China Photographic Publishing House, 2001.

[6] Plaker, David. Capturing Colour. Beijing: China Youth Publishing Group, 2008.

[7] Braga B M D M. CREATIVE POSSIBILITIES OF ANALOGUE PHOTOGRAPHY: A DIALOGUE BETWEEN THE PAST AND THE PRESENT IN THE ERA OF DIGITAL IMAGES[J]. Proceedings of World Congress on Communication \& Arts, 2014, 7

[8] Wang Z, Chao K T. Analysis of the Current Development Situation of China Concept Photography in the Digital Photography Era[J]. Art \& Design, 2014

[9] Mason A, Schäfer S. Focus on the Future: Creating Born-Digital Standards for Large-Format Photography[J]. 2013:183-185(3). 